\section{UN NUEVO LAICADO PARA UN NUEVO SIGLO}

Autor: Pedro León y Francia. Ex Presidente del Foro de Laicos y de la Comisión Justicia y Paz de España.
Pedro León es un laico comprometido en el camino del Pueblo de Dios. Desde su vivencia presenta lo que fue el laico antes de Vaticano II y los nuevos horizontes abiertos por la eclesiología de comunión del Concilio. A partir de aquí señala los ámbitos plurales en los que ha de ejercerse la responsabilidad evangelizadora que el laico tiene y las cualidades y actitudes que la deben acompañar: hombre de oración, con buena formación, dialogante... De ahí nos señala las dificultades que han de afrontar, emanadas de fuera de la Iglesia o del interior de la misma.

DOI: https://doi.org/10.52039/seminarios.v47i159.986

\title{
INTRODUCCIÓN
}

Cuando se me planteó la oportunidad de escribir una colaboración, relativamente extensa, para una revista dedicada al estudio e investigación sobre las vocaciones y ministerios en la Iglesia, a pesar de preferir en general la comunicación verbal y directa con los oyentes, no pude rechazar la invitación pensando que con esta modesta aportación podría ayudar a quienes estudian estos temas y a quienes trabajan para las vocaciones a valorar la vocación laical en el ámbito de la evangelización, misión que tenemos todos los bautizados.

Por descontado quiero que quede muy claro que cuanto aquí se escribe responde a mi personal interpretación del papel que el laicado de ambos sexos, sin distinción alguna, debe desempeñar en este momento clave de la historia para responder generosamente a las necesidades de todo tipo, espirituales y materiales, en las que se debate el 
mundo en que vivimos. Con ello deseo aclarar que mi opinión no tiene vinculación directa con los planteamientos que puedan hacer las dos organizaciones católicas que por designación de nuestros obispos, inmerecida desde mi punto de vista, me ha tocado presidir durante los últimos años. Evidentemente mucho de lo que yo expongo lo he aprendido tanto en "Justicia y Paz" como en el Foro de Laicos de España; ya que las experiencias vividas son inolvidables y han supuesto un auténtico regalo, con su parte de privilegio y a la par de responsabilidad, pero en definitiva un enriquecimiento inmenso de mi persona.

Situado desde el cariño y fidelidad a la Iglesia

De entrada proclamo mi cariño y fidelidad a la Iglesia, así como el respeto que me merecen tanto la jerarquía como los sacerdotes, religiosas, religiosos y laicos, mujeres y hombres. Pero ese cariño me impulsa precisamente a desear para la Iglesia de Jesús, lo mejor en todos los órdenes. Teniendo en cuenta la debilidad humana que nos lleva a cometer errores que puedan dificultar o simplemente oscurecer la difusión del Mensaje más perfecto, el de Jesús de Nazaret, para la plena realización de los seres humanos, me apoyo en un canon, ignorado por muchos, el 212, que en esencia dice que el cristiano debidamente formado, ante determinadas situaciones o actuaciones de la Iglesia, tiene el derecho y en ocasiones incluso el deber de criticar lo que sea digno de rechazo o revisión, buscando siempre, con criterio constructivo y con pleno respeto a la jerarquía, el bien de la comunidad.

Quisiera ayudar a una reflexión serena y positiva y a crear una auténtica y formada opinión pública en el seno de la institución eclesial que aporte posibilidades de un diálogo sincero y abierto, para, sin eludir el papel de la jerarquía en la toma de decisiones finales, contribuir corresponsablemente a la elaboración de las mismas.

Teniendo en cuenta las diferencias culturales, sociales, económicas y por descontado religiosas, prefiero con un criterio práctico referirme a la situación en España, por tener un mayor conocimiento directo de las coordenadas en las que se desarrolla.

Interesa conocer bien el punto de partida, es decir cual es la situación real de nuestro país desde la óptica religiosa. Utilizando estadísticas oficiales de los propios organismos eclesiales católicos, universidades incluidas, podemos considerar los datos siguientes: bautizados católicos $=82 \%$ de la población. De esta cifra se autodeclaran libremente como "practicantes" (y ya sabemos lo que para muchos supone ser prac- 
ticante...) un $32 \%$. Demos un paso más; si consideramos el mundo juvenil, es decir el comprendido entre 15 y 25 años, exactamente igual hombres o mujeres, la muestra arroja algo preocupante, solo se declaran "practicantes" el 12\%, cantidad que aún desciende al 10-11\% en las grandes ciudades. Si a esos jóvenes de los dos sexos se les pregunta cuantos siguen todas las normas oficiales de la Iglesia en materia de moral sexual, la cifra se reduce a un $3,5 \%$. Saquemos todos las consecuencias oportunas de esa realidad, porque ésa es nuestra Iglesia del futuro inmediato, al menos en el primer tercio de este nuevo siglo XXI.

Conclusión lógica: Si el Mensaje transmitido es el mejor ¿qué es lo que ha fallado? con toda evidencia y aún teniendo presente las nada favorables situaciones externas ambientales, hemos sido los transmisores en los distintos niveles los que nos hemos equivocado y pese a la innegable buena voluntad no hemos sabido hacerlo, para contrarrestar la tremenda presión exterior y mantener en el sencillo pueblo de Dios la vivencia permanente de la Fe.

En este marco de luces y sombras se desarrolla mi reflexión y por supuesto, coherentes con la doctrina que profesamos, tenemos que mantenernos siempre abiertos a la Esperanza. Tras la noche siempre vuelve a salir el sol y ya incluso un gran escritor no creyente, Octavio Paz decía que "quien ha visto la Esperanza no la puede olvidar".

\section{El laico}

Pasemos a otro tema: ¿qué es un laico? No nos sirve la triste definición excluyente utilizada tantos años la que decía: que es "el no clérigo o consagrado". Según "Christifideles laici" es un experto en humanidad que debe desarrollar el proyecto de Dios en el mundo. La condición secular es un auténtico espacio teológico y dentro de la igualdad esencial de todos los cristianos, todo laico está llamado también a la plenitud de la santidad.

No podemos olvidar los laicos, hombres y mujeres, que antes que cristianos somos personas, seres humanos, que desde nuestra secularidad queremos experimentar al Dios de la Historia.

Felizmente el concepto de laicado ha ido avanzando lentamente, demasiado lentamente, a lo largo de los siglos. Desde el penoso dicho de Graciano en la edad antigua, de que los laicos si hacen el bien y evi-

Todo laico está llamado a la plenitud de la santidad

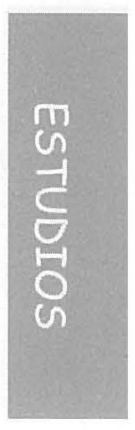


tan el mal se pueden salvar, pasando por la triste consideración de la mujer, que aparte de ser inferior al hombre, todavía en la Edad Media se discutía en el ámbito religioso si tenía o no alma...

Ya en el siglo XIX el Papa Pío IX llegó a afirmar en público que la Tradición era El sólo. A mediados del siglo XX en la encíclica " Pacem in terris" del inolvidable Juan XXIII se alude por primera vez a la expresión Derechos Humanos, clave en la cultura moderna de la humanidad. Tuvo que ser el Concilio Vaticano II el que afirmase que no hay Iglesia sin laicado y que en la propia Institución eclesial hay una unidad de misión y diversidad de funciones, abriéndose paso a una nueva eclesiología, la del Pueblo de Dios.

Pasos para la nueva realidad del laicado

El sínodo de los laicos de 1987 defiende la dignidad igual del hombre y la mujer (aunque elude entrar en los temas del celibato y la ordenación femenina). Insiste en el valor del diálogo y la tolerancia, en la idea de servicio y en una evangelización basada en el amor, la paz, la justicia y la libertad.

En el Foro Internacional de Laicos de 1994, el Cardenal Pironio habla del laicado como una nueva primavera eclesial y en la Congregación General de la Compañía de Jesús, celebrada en 1995, se insiste en la necesidad de desclericalización de la Iglesia y aumentar la cooperación con los seglares.

Completaremos esta breve información con dos textos de la Conferencia Episcopal Española; "Cristianos Laicos, Iglesia en el Mundo" de 1991 (CLIM) y el Plan Pastoral de la CEE para 1994; en este último se invita a "impulsar una participación laical con audacia" y en el CLIM se insiste en la corresponsabilidad en la Iglesia, la no búsqueda del poder, el valor aceptado de las dos vías de actuación, Iglesia de la mediación e Iglesia de la presencia, no renunciando a una presencia pública de la Iglesia y de lo que es más sugerente en nuestro caso, que los laicos ayuden a la formación de los sacerdotes en aquello específico que puedan aportarles.

\section{II. Ámbitos de actuación del Laicado}

Desde luego, aun aceptando que el campo ordinario y mayoritario de acción será el mundo, acepción que comprende todas las actividades no estrictamente religiosas, eso no quiere decir en modo alguno 
que el ámbito eclesial, dentro de la institución se abandone en manos de jerarquía y clérigos ya que se correría el serio peligro de funcionar en paralelo y no en permanente interacción y diálogo.

La sociedad actual de nuestro país está pasando por una etapa de secularización acelerada y ha recorrido en 20 años el camino que otros países de nuestro entorno han hecho en un siglo. Ciertamente la cultura española tiene una base cristiana pero la realidad, no importa la ideología del Partido que ocupe el poder, es muy diferente, sobrepasando incluso en alejamiento de vida cristiana a países que contemplábamos como prácticamente agnósticos hace unos años. Baste como ejemplo, el que tenemos el índice de natalidad más bajo de Europa (1,2 hijos por mujer) con todo lo que ello comporta y estamos lamentando la pérdida mayoritaria del mundo obrero y de la juventud incluida la femenina. Contemplemos desde el coro el panorama que ofrecen nuestros templos: calvas, cabellos blancos o teñidos... Si esto no cambia, ¿qué pasará dentro de diez, quince, veinte años?.

Cada uno de nosotros, mujeres y hombres cristianos, convencidos de esa Fe que nos ha sido regalada, tenemos que examinar cuáles son nuestras responsabilidades evangelizadoras y en qué campos vamos a desplegarlas. Ante todo y con carácter general, hemos de mostrar una coherencia lo más honrada posible entre lo que decimos creer y defender y nuestra actuación en la dura realidad. Todos tenemos que asumir una tarea efectiva y no sólo teórica, asumiendo riesgos inevitables y conforme a la vocación y capacidad de cada uno. Habrá momentos de euforia, real o aparente y momentos de desánimo y cansancio, pero no estamos sólos. El Espíritu de Dios nos acompaña, nos confortará y nos relanzará.

Comencemos por la familia:

La vida matrimonial vivida con alegría, con apoyo mutuo, en pleno disfrute de todos los momentos de placer que puede y debe aportar, mejorando las relaciones con los hijos, responsable y generosamente aceptados, asumiendo que no son algo que nos pertenezca y que con nuestra ayuda deben aprender a vivir su propia vida, tanto espiritual como de relación humana y social. Fomentando el cariño y aceptación permanente de los ancianos de los que somos ampliamente deudores y a los que no podemos marginar de nuestras vidas.

La vida profesional y laboral: Asumiendo el trabajo con una idea de servicio a la sociedad y no sólo por su compensación económica; 
viviendo éticamente las relaciones vinculadas a las tareas de cada día, asumiendo compromisos sindicales, patronales o de comité de empresa, para defender siempre las posturas más justas y razonables.

La participación política y ciudadana, no limitándonos a ejercer el derecho de voto sino contribuyendo al desarrollo de la democracia, la defensa de los derechos humanos y la dignidad de la persona, aceptando con respeto la existencia de un sano pluralismo. En definitiva, trabajando por los demás ya sea en agrupaciones políticas, asociaciones de barrio, asociaciones de padres, comunidades de vecinos, consejos escolares, ONGs, asociaciones culturales o deportivas, etc.

Una especial atención ha de recibir el ámbito cultural y educati$v o$, que constituye una palanca clave para el desarrollo futuro, tanto de la persona como del país entero, en un avanzar hacia metas que fomenten y cultiven nuestra sensibilidad. Tanto las ciencias con su importancia enorme en el desarrollo y la necesidad de seguir de cerca su evolución para evitar su deshumanización, como las humanidades propiamente dichas, que nos ayudan a conocer, valorar y defender la belleza de la creación y del arte en sus diferentes aspectos.

Finalmente y no por ello lo menos importante el prestar la debida atención al mundo variopinto de los medios de comunicación que detentan un poder e influjo mediático inmenso en nuestra sociedad.

Imaginemos lo que una actitud cristiana, clara y comprometida, puede lograr en todos los ámbitos que hemos citado y cómo se podría avanzar hacia un mundo mejor y más justo si fuésemos capaces de iluminar nuestras acciones con la luz del mensaje por excelencia, el del Amor.

\section{Rasgos característicos}

El compromiso exige determinadas cualidaes en el laico: oración, formación...
El laico cristiano, tanto hombre como mujer, para poder comprometerse en profundidad en los diferentes campos de evangelización, ha de reunir una serie de cualidades, en mayor o menor grado, ya que sin ellas o al menos sin la voluntad de ir adquiriéndolas día a día, difícilmente podrá cumplir con la tarea a la que su vocación concreta le impulsa a realizar sin que el orden de exposición prejuzgue su importancia. Enuncio las que me parecen más relevantes:

Oración: tiene que estar en la base de esa síntesis Fe-Vida que se nos pide. Ponernos en las manos de Dios, pero no de un Dios lejano, 
sino de ese Dios-Padre cariñoso, pendiente de nosotros y que conoce mejor que nadie nuestras necesidades y debilidad para afrontar situaciones difíciles. Transmitir el mensaje de Jesús, con la ayuda permanente del Espíritu Santo es algo a lo que la Eucaristía y la oración confiada nos debe animar y naturalmente supone la apertura hacia adelante, transformando la fe en esperanza y viviéndola en la generosidad y en solidaridad con todo el mundo.

Formación: Si queremos que el diálogo Fe-Cultura, que ha de atravesar constantemente nuestra vida, sea más serio y profundo, hemos de procurar alcanzar unos niveles dignos, tanto en nuestra cultura religiosa como en la que podíamos definir como civil o profesional.

Dedicación: La labor evangelizadora, en cualquiera de las formas que adopte, requiere una dedicación suficiente, responsable y constante. Aunque en lo que al tiempo se refiere, lógicamente será inferior a la de nuestro trabajo de cada día, la seriedad en el compromiso ha de ser equiparable. Esto quiere decir que, por ejemplo, un trabajo de voluntariado al servicio de los demás, no debe concebirse como una diversión o un "hobby" cualquiera, sino que debe abordarse con la misma seriedad que nos exigimos en la vida familiar o profesional.

Talante de diálogo: Es esencial para acercarnos a los que nos rodean, respetando siempre sus personas y ofreciendo nuestra ayuda, consecuencia de nuestra vivencia cristiana. Ha de ser un diálogo reflexivo, responsable, realista, racional y por supuesto riguroso en el sentido de dotado de objetividad.

Aceptación del pluralismo social: Hemos de ser realistas y tomar conciencia de que somos una minoría y de que el Mensaje que transmitimos lo ofrecemos huyendo de toda imposición, pero convencidos de que si se acepta en libertad, estaremos contribuyendo a la plena realización del ser humano y la defensa incondicional de su dignidad esencial.

Apoyo necesario en un grupo: Es muy amplia y difícil la tarea evangelizadora como para abordarla individualmente. Necesitamos tener junto a nosotros personas que nos sostengan en los momentos de debilidad, nos animen, nos hagan caer en la cuenta de que no tenemos que buscar un éxito humano fácil a nivel personal. Esta ayuda se encuentra en los grupos, movimientos y asociaciones de todo tipo, que elijamos como más acordes con nuestra particular vocación y en los que nos integremos libre y generosamente, aceptando dar y recibir en un ámbito fraternal.

La tarea evangelizadora no se aborda individualmente 
Sensibilidad y solidaridad efectiva con el mundo de los marginados: Comenzando por adoptar, en la medida de nuestras posibilidades y generosidad, un camino o estilo de vida que se puede concretar en austeridad para compartir, avanzando siempre aunque a veces sea lentamente. Una auténtica opción por los pobres que nos ha de llevar a contemplar desde su óptica ese fenómeno tan actual y lleno de contradicciones como es la globalización. Incluyamos también el tratamiento de la deuda externa del tercer mundo, el comercio justo, la Banca ética, la defensa de un estado de bienestar generalizado, etc. y en definitiva la lucha contra las desigualdades y discriminaciones de todo tipo.

No violencia: Hemos de adoptar una clara y definida postura de rechazo a la violencia, venga de donde venga y una defensa generosa de la vida y su dignidad esencial. Un rechazo a todo tipo de racismo, xenofobia o nacionalismo salvaje, entendiendo por tal el que se apoya o promueve cualquier actividad de índole terrorista. Los cristianos tenemos que ser sembradores de paz y de concordia en todas las situaciones en las que se desenvuelva nuestra existencia.

Atención a los signos de los tiempos: Expresión muy utilizada por el Papa Juan XXIII y que puede y debe tener una amplia lectura y

Atento a los signos de los tiempos

Abierto a todos repercusión social. No entiendo cómo nos referimos a la necesidad de inculturar la Fe en las distintas partes del mundo, cosa por otra parte indispensable, y no nos planteamos el inculturar nuestra evangelización en el mundo de hoy, un mundo en proceso de cambio acelerado, tanto en el fondo como en la forma. No se trata de rechazar unos dogmas e inventar otros, sino de saber, en el lenguaje de hoy y adaptado a la mentalidad actual, presentar el Mensaje fundamental de Jesús. La Iglesia a lo largo de los siglos ha evolucionado y aun tiene que seguir evolucionando, aunque sólo sea por no quedar rezagada como suele ocurrir siempre ante los procesos vertiginosos de cambio que estamos realmente viviendo. Por descontado que hay que mantener lo esencial, el depósito auténtico de la Fe, sin embargo hay que estar dispuestos a afrontar con serenidad pero con audacia las nuevas situaciones y proponer soluciones adecuadas a los nuevos problemas planteados.

Sensibilidad ecuménica: A pesar de algún retroceso aparente, motivado tal vez, más que por el fondo de planteamientos recientes, por la forma y sobre todo la inoportunidad, hemos de embarcarnos, con plena confianza en el Espíritu, en la aproximación ecuménica, que 
comienza por conocernos, continúa por respetarnos, avanza queriéndonos y puede llegar a construir entre todos una unidad plena en la Fe.

Este itinerario es, salvando las diferencias fundamentales, válido también para con las religiones no cristianas.

Sensibilidad ecológica: Para nosotros debe derivar directamente de nuestra responsabilidad y respeto a la Creación y al Creador. Una cosa es que la Creación esté al servicio del ser humano y otra es que éste abuse de la misma y no respete a la naturaleza, al mundo animal e incluso al vegetal.

Vivir la libertad de los hijos de Dios: Ejerciendo un sentido crítico auténtico, siempre constructivo y respetuoso con las personas, buscando el bien común y estando dispuestos a pedir perdón y a otorgarlo cuando cometamos errores o los cometan con nosotros.

Mantener serenidad en la vida política: Partiendo del hecho históricamente contrastado de que la democracia es el menos malo de los sistemas políticos, hemos de implicarnos para lograr que sea cada vez más auténtica, no descalificando por sistema y sin una evaluación imparcial a los que profesan ideas políticas distintas de las nuestras y por supuesto no mezclando partidismo y evangelización. Jamás un cristiano debe buscar el poder por el poder, sino siempre movido por una idea de servicio a la comunidad y de respeto a sus conciudadanos, tratando de ser en su actuación objetivamente justo.

Podríamos continuar enumerando otras realidades como por ejemplo, vivir con actitudes humildes y sin buscar sólo el dinero o el éxito personal, valorar más y mejor el cuerpo y la sexualidad humana, etc. pero para no extender demasiado estas reflexiones me parece oportuno cerrar aquí este apartado.

\section{Dificultades}

No se oculta que el despliegue de todas estas cualidades por parte de las mujeres y hombres cristianos, en un trabajo serio y permanente, encontrará, mejor dicho ya lo viene encontrando, una serie de dificultades, no sólo en la sociedad civil, cosa por otra parte previsible a la vista de la deriva materialista y descristianizada que va tomando, sino y esto es más triste, en la propia institución eclesial a la que pertenecemos y que por razones diversas, a veces realmente incomprensibles

Dificultades de fuera y de dentro de la Iglesia 
para una mentalidad laical, frena o pone trabas a tareas evangelizadoras emprendidas legítimamente por personas no consagradas y que no disponen en consecuencia de la tan utilizada potestad de mando o gobierno.

Creo sinceramente que una breve consideración de estas actitudes, invitando a la reflexión por parte de quien se vea de alguna forma reflejado en ellas, es indispensable. Así podremos ayudar a que nuestra Iglesia y no olvidemos que Iglesia somos todos los bautizados, asuma la necesidad de reconsiderar determinados planteamientos, que por supuesto no tienden a alterar lo esencial de la fe cristiana. Esta actitud contribuirá a la indispensable evolución e incluso a la eliminación de elementos ideológicos o materiales, que actúan como verdaderos parásitos de la vida cristiana, dificultando su sano crecimiento y desarrollo.

Falta una plena credibilidad de la Iglesia, que actualmente se tam-

Superar la incoherencia entre lo que se predica y lo que se practica

Ser sensibles a no confundir entre servicio y poder balea en algunos momentos, en general por incoherencias entre lo que se predica a los fieles, e incluso a los que no lo son, y lo que luego se realiza en la práctica; ejemplos numerosos podrían ilustrar este punto: la proclamación de los derechos humanos, que no siempre se respetan en el interior de la propia comunidad eclesial, cuando se toman decisiones en base al principio de autoridad, sin permitir una defensa suficiente del sancionado; la defensa de la libertad de los hijos de Dios, que tantas veces se ve limitada por la propia jerarquía competente, incluidos los campos de investigación teológica, genética, etc., en los que antes de una toma de decisiones habría que profundizar mucho más en el examen de la evolución y circunstancias de cada caso o situación.

Se parte siempre de un error fundamental del que todos somos responsables, jerarquía, clero y laicado en el campo creyente y también los que se proclaman seguidores de otras doctrinas religiosas, los agnósticos y los ateos. Nos referimos a la utilización de la frase:

"La Iglesia dice, o la Iglesia condena..." en lugar de decir tal o cual persona concreta u organización con autoridad, dice o condena... ya que Iglesia somos todos los creyentes, tanto el que censura como el censurado, aunque desempeñemos funciones distintas en el seno de la comunidad eclesial.

Es importante tener esto presente porque así se evitarían tristes equívocos que no ayudan a la respetabilidad de la Iglesia. No puedo evitar sentirme también dolido cuando oigo la expresión "los curas 
dicen o los obispos se oponen". Todo esto debería conducirnos a una seria reflexión sobre la confusión entre servicio y poder.

No siempre se sirve mejor a la comunidad que uno tiene encomendada ejerciendo pura y simplemente la autoridad, tentación por supuesto muy humana y que todos hemos experimentado en diferentes momentos de nuestra vida.

Deseo que quede muy claro que esta reflexión sobre la manera de ejercer la autoridad no implica el negar la legitimidad de su existencia. Toda comunidad humana necesita un aglutinante doctrinal, unas normas que lo interpreten y desarrollen y unas personas al frente que asuman la pesada y delicadísima carga de ayudar a todos los miembros a ir avanzando y si se trata de una comunidad cristiana el avance y el ejercicio del gobierno ha de estar impregnado sobre todo de auténtico amor.

Derivado de esta concepción de autoridad nuestra religión cristiana ha acuñado, a partir del Concilio Vaticano II, otro concepto aplicable al Pueblo de Dios y es el de Corresponsabilidad:

Entendemos que esta palabra nos llama a sumarnos, participando en plenitud tras un sano discernimiento cristiano, en las decisiones que se adopten por la jerarquía competente en cada caso, asumiendo deliberadamente lo acordado y en consecuencia sintiéndonos corresponsables de su aplicación práctica. Esto supone claramente un escalón superior al mero ayudar, colaborar e incluso apoyar; significa un sentirnos parte activa en la formación de la decisión. Ante esta definición invito a que, con la mano en el corazón y en lo que nos es dado conocer de la marcha de nuestra comunidad eclesial, digamos si se cumple o no en la práctica. Mi experiencia no es nada optimista al respecto, pese a que llevamos más de treinta años hablando del tema.

Falta de confianza en el laicado: En el fondo late algo que los laicos notamos claramente y es lo que me atrevería a llamar "complejo de superioridad" del clérigo en una infravaloración del laico y más aún si es mujer. En muchos casos este fenómeno es inconsciente y sin la menor voluntariedad pero efectivamente existe. Ejemplos hay para todos los gustos y todos recordaremos alguno, sin lugar a dudas.

Falta de sencillez por una mal entendida idea de mantener tradiciones obsoletas a estas alturas, la impresión que producen los títulos vinculados a los cargos eclesiásticos en sus distintos niveles, es generalmente negativa. Tanto "eminentísimo", "reverendísimo" (o en su 
Eliminar títulos rimbombantes poco acordes con la sencillez evangélica

Documentos más breves $y$ asequibles para todos acepción más modesta "reverendo"), "excelentísimo" e "ilustrísimo" no encuentran un fácil encaje evangélico y de entrada les distancia del pueblo sencillo que les asimila a las autoridades civiles y sus titulaciones honoríficas. A estos adjetivos rimbombantes se une frecuentemente el cuasiculto que se rinde a la autoridad eclesial por parte de la "corte" que la rodea y que incluso a veces dificulta su contacto directo con el pueblo fiel. Y no hablemos del vestuario utilizado en las grandes ceremonias. La modesta túnica de un pescador se ha convertido a veces en una suerte de manto imperial y para colmo rematado por un extraño tocado de cabeza, de origen probablemente egipcio y que al cristiano de a pie no le aporta nada positivo y sí alguna sonrisa contenida. No digamos nada de la impresión que estos espectáculos procesionales producen en la mayoría alejada de la Iglesia. ¿En qué siglo estamos? Sé que los especialistas en liturgia pondrán el grito en el cielo ante estas opiniones de un laico ignorante, pero ¿de verdad han recogido la reacción y el sentir de la gente sencilla ante todo lo que aquí citamos? ¿Es así como queremos evangelizar? ¿Jesús se vistió alguna vez de sacerdote de su tiempo para transmitir su doctrina?...

Falta de sentido pedagógico de los numerosos (incluso excesivos) documentos elaborados, tanto por la Santa Sede, como por las diferentes conferencias episcopales. Su extensión, con frecuencia desmesurada, hace que la inmensa mayoría de los fieles no los lean enteros y se limite a conocer resúmenes o comentarios de la prensa escrita, que no siempre es objetiva y resalta determinados párrafos, según la ideología del periodista o del medio en el que escribe.

La redacción, a veces confusa, generalmente reiterativa y lo que es más grave en una permanente mezcla de texto original y de citas bíblicas, conciliares o de otros documentos, dificulta una lectura fácil y asequible a todos. A título de ejemplo y sin que esto suponga el menor desprecio al fondo muy valiosos del documento, les invito a leer la última carta apostólica "Al comenzar el nuevo milenio". ¿De verdad cree alguien que el pueblo creyente a quien va dirigida la va a leer tal y como está elaborada, y teniendo en cuenta su extensión? Pienso que sería mejor algo breve, conciso y en lenguaje asequible y con las citas al final del texto.

Falta de una mayor participación del Pueblo de Dios en la vida ordinaria de la Iglesia. Una de las instituciones en que se podría vivir 
esa participación son los consejos pastorales de parroquias. Pues bien, el actual Código de Derecho Canónico en su canon 536, los califica de "meramente consultivos". Se ve que la palabra consultivo parecía todavía suave a los redactores y por eso se refuerza con el adverbio. ¡Qué triste! Es cierto que con posterioridad, sin anular el canon en su redacción, en otros documentos romanos se admite la posibilidad de que algún consejo sea decisorio, pero la verdad es que yo no conozco ninguno, abierto a los seglares, excepto los de carácter económico. Sólo lo son cuando el talante de quien los preside acepta humildemente que si la mayoría moral se decanta por un tipo de acuerdo, él se suma con su autoridad al mismo, aunque no coincida exactamente con lo que hubiera sido su deseo personal. Pensemos que en ningún Consejo Pastoral se debaten profundos temas dogmáticos o de costumbres sino que más bien tratan asuntos vinculados al día a día normal de la vida eclesial, en el nivel de actuación propio de cada Consejo.

Confundir decisión con participación. Ejemplo elemental: Sin poner en duda el que la designación de obispos, pertenece en estos momentos al Papa, (no ha sido siempre así en la vida de la Iglesia) y en que su consagración debe ser naturalmente efectuada por otro obispo. ¿Por qué no se acepta que los fieles a través de sus organizaciones, movimientos, consejos pastorales, parroquias, etc. puedan presentar candidatos que se estimen idóneos tanto por sus dotes personales como por conocer mejor la vida religiosa y social de la Comunidad que están llamados a presidir?

Falta una visión aperturista de la jerarquía y buena parte del clero hacia una pluralidad social e ideológica en la sociedad española, con la que hay que saber dialogar, sin pretender privilegios pero defendiendo legítimos derechos y sin dar una sensación victimista, "no nos quieren", pero sin pretender imponer nada partiendo de una prepotencia que la mayoría social rechaza.

Un no rotundo al secretismo eclesial que a la larga causa mayores perjuicios porque la falta de información y diálogo provoca la extensión malévola del rumor y la mentira con el daño consiguiente. Puede haber ocasiones en que la prudencia exija el silencio pero no debe ser la norma general.

Falta por último una matización sobre la doble consideración de Orden y Jurisdicción. No parece lo más adecuado conforme a la idea universal de justicia que el juez sea la misma autoridad, que además es

Necesidad de visión aperturista hacia la pluralidad social e ideológica 
la que ha promulgado la ley. No cabe analogía con la sociedad civil, en el sentido de tener un parlamento legislador, pero siempre es bueno que intervengan lo más posible órganos colegiados, ya que al juzgarse actitudes vinculadas al cumplimiento de la ley, se corre el peligro de que al final el proceso concluya en un ordeno y mando, terminología que por otra parte no está ausente en palabras equivalentes en muchos documentos oficiales emanados de la jerarquía.

En definitiva lo más duro para un cristiano que aspira a implicarse en tareas evangelizadoras, es romper con la equivalencia Iglesia $=$ conservadores o Iglesia $=$ derecha. Jesús de Nazaret no fue ni un conservador ni un defensor de las clases más pudientes, por el contrario subrayó en numerosas ocasiones su preferencia por los pobres y marginados, sin que esto suponga el rechazo radical de los instalados, pero sí la invitación permanente a compartir lo que poseen y a implicarse en el servicio de los más débiles.

\section{CONCLUSIONES}

De la lectura de todo lo anterior, es fácil deducir el cambio importante que hemos de acometer en la Iglesia a todos los niveles, aceptan-

Aceptar correr los riesgos del cambio do perder algo de nuestra pétrea seguridad, corriendo riesgos que evidentemente no sufriríamos si nos quedásemos cruzados de brazos ante una realidad desoladora.

Tenemos que vivir la fe en el escenario del pueblo, allí donde Dios se hace presente en los seres humanos creados a su imagen y semejanza. Esta vivencia comprometida y directa nos tiene que impulsar a compartir el destino de la humanidad, que precisamente si tenemos una auténtica Esperanza con la asistencia del Espíritu, ha de ser positivo y luminoso. Tenemos muestras admirables en la vida de una Iglesia en la que han surgido madres Teresas de Calcuta, misioneros, sacerdotes, religiosos, religiosas y laicos de ambos sexos, que han llegado a sacrificar el bien más preciado, su vida, por servir a los marginados, así como numerosos voluntarios en tareas difíciles. Ante estos casos los no cristianos se preguntan qué o quién impulsa a realizar estos actos de supremo Amor. En el fondo en ese momento para muchos está latente la convicción o al menos la duda, de que hay un Dios, motor de esas conductas modélicas para la humanidad. 
Hemos de esforzarnos por atraer a los que se alejan de nosotros por sentirse decepcionados ante nuestra vida de cada día y la ya citada falta de coherencia. Los laicos, mujeres y hombres, no podemos quedarnos impasibles ante los impulsos involucionistas que de vez en cuando sacuden nuestra querida Iglesia. Pidamos que se cumplan muchas de las ideas y decisiones que figuran en los documentos oficiales y que luego no se aplican en la realidad.

Los laicos de ambos sexos hemos de desempeñar el papel de verdaderos puentes entre la Iglesia y el mundo, para que le llegue el Mensaje y en esta tarea hemos de tomar iniciativas audaces que no tienen por qué constituirse en una religión a la carta, tal y como indica "Christifideles Laici". No se trata de poner un vestido cristiano a la humanidad, sino como muy acertadamente definió la Acción Católica Italiana, de hacerle una auténtica transfusión de sangre.

$\mathrm{El}$ trabajo es arduo y tardaremos en ver sus frutos pero ya hay que empezar a sembrar de una manera diferente la doctrina en la que creemos firmemente. Mujeres y hombres cristianos comprometidos, no somos como muchos nos consideran, el brazo largo de la jerarquía. Actuamos por un impulso directo e individual que arranca de nuestro bautismo contando con todas las ayudas y apoyos a los que nos hemos venido refiriendo y en una plena comunión esencial con la jerarquía de la Iglesia.

Quiero concluir con una frase que me ha impresionado tanto que la utilizo siempre en mis reflexiones públicas. Es del obispo Pedro Casaldáliga, ese catalán y español universal, que es una invitación al examen personal sobre nuestra conducta de cada día en la línea del compromiso. "Dime como vives hoy y te diré si valen tus sueños de mañana".

Ser los laicos puentes entre la Iglesia y el mundo 